\title{
Lexical stress and lexical access: Homographs versus nonhomographs
}

\author{
LARRY H. SMALL and STEPHEN D. SIMON \\ Bowling Green State University, Bowling Green, Ohio \\ and \\ JILL S. GOLDBERG \\ Chedoke-McMaster Hospitals, Hamilton, Ontario, Canada
}

\begin{abstract}
The purpose of the study was to examine the perceptual effects of altering lexical stress during word recognition. A detection task was utilized to measure subjects' speed of response to target phonemes preceded by two-syllable homograph and nonhomograph words. These experimental words were pronounced with correct/incorrect lexical stress. When a nonhomograph was misstressed, a nonsense word was the result. When a homograph was misstressed, another English word resulted. Examination of subjects' speeds of response to target phonemes preceded by correctly/incorrectly stressed nonhomograph words indicated slower speed of response when the stimulus word was stressed incorrectly; word recognition appeared to be affected when a subject heard a misstressed nonhomograph (a nonsense word). However, subjects' speed of response to target phonemes following correctly/incorrectly stressed homographs were similar. Mispronounced homographs did not appear to impede word recognition. It was possible that when subjects heard a misstressed homograph (another English word), they relied more upon the prosodic contour for word recognition.
\end{abstract}

Although it is generally known that prosodic information is essential during word recognition, it is not clearly understood how prosodic cues such as lexical stress and sentence accent operate in speech perception. The importance of stress in speech perception has been reviewed quite extensively by Lehiste (1970). Lehiste states that stress is perceived largely in terms of change in the speaker's fundamental frequency, with duration of speech segments playing a smaller role. According to Lehiste, listeners react to a speaker's vocal effort in perception of stress, as opposed to actual changes in vocal intensity.

It has been suggested that the mental lexicon is organized, in part, by the stress characteristics of words (Brown \& McNeill, 1966; Fay \& Cutler, 1977). Fay and Cutler examined speech errors (malapropisms), involving the substitution of one word for another with a different meaning, for example, "equivocal" for "equivalent." The stress pattern was the same for the intended word and the substitute $98 \%$ of the time. Brown and McNeill, in exploring the "tip-of-the-tongue" phenomenon, discovered that when subjects were in a tip-of-the-tongue state, the words they offered for the intended target shared lexical stress $74 \%$ of the time.

Several studies have attempted to detail the importance of lexical stress during word recognition. Cutler and Foss

Stephen D. Simon is now at National Institute for Occupational Safety and Health, Cincinnati, Ohio. L. H. Small's mailing address is Department of Communication Disorders, 338 South Hall, Bowling Green State University, Bowling Green, OH 43403.
(1978) observed that reaction times to a phoneme target were faster when the target-bearing word was stressed than when the target-bearing word was not stressed, regardless of the form class of the word, that is, whether the word was a content or function word. Cutler and Foss suggested that the most important element of a seittence usually receives stress, and that the most important element may be determined more by the semantics and pragmatics of a sentence than by the form class of the item. Likewise, Cole and Jakimik (1980) reported that the number of listener detections of mispronounced targets in stressed syllables was greater than detection of targets in unstressed syllables, independent of the position of the syllable in the word.

Utilizing a shadowing task, Small and Bond (1982) reported that subjects had difficulty shadowing two-syllable words (embedded in a prose passage) in which lexical stress was shifted from the first to the second syllable, or vice versa, for example, "people" to /pepul/, or "decide" to /disad/. These mispronunciations involved altering vowel quality; full vowels were spoken in their reduced form and reduced vowels were given full weight, as indicated above. Subjects restored the stress errors to their original form, while shadowing, only $22 \%$ of the time, whereas they repeated the misarticulated stress pattern $39 \%$ of the time. The other $39 \%$ of the subjects' shadowed responses consisted of failure to respond, or construction of new words to fit the syntactic/semantic frame of the passage being shadowed. This suggested that when stress was physically altered, listeners had a difficult 
time trying to cope with the distorted speech signal. It was not clear whether subjects' responses were due strictly to changes in lexical stress, or whether their responses were a result of both lexical stress and vowel quality changes.

In a related study, Cutler and Clifton (1984), indicated that when two-syllable words, presented in isolation, were mispronounced by shifting lexical stress from one syllable to the other, subjects' reaction times to correctly stressed words were significantly faster than reaction times to incorrectly stressed words; word recognition was hampered when a word was misstressed. However, Cutler and Clifton suggested that when a change in lexical stress also involved a change in vowel quality, word recognition was more affected than when a change in lexical stress involved no change in vowel quality.

The studies by Small and Bond (1982) and Cutler and Clifton (1984) indicate that shifting lexical stress in twosyllable words affected word recognition. However, in these studies, the experimental stimuli involved nonsense words due to shifts in lexical stress. It is difficult to determine whether any disruption in lexical access was due solely to the stress shift itself or to the fact that nonsense words were apparent. It would therefore be interesting to examine stimulus items that result in English words when lexical stress is shifted. For this reason, homograph stimuli were adopted for analysis in the present investigation.

A homograph is a word with the same spelling but with different meaning and origin, CONtract and conTRACT, for example. Most often, homographs with first-syllable stress are nouns, and homographs with second-syllable stress are verbs. Even though the use of homographs ensures real-word stimuli, when stress is shifted, the vowel quality in each syllable of a two-syllable homograph normally changes when lexical stress is shifted to the other syllable.

In order to further define the role of lexical stress in word recognition, it would be of interest to examine the perceptual effects of altering lexical stress for both homograph and nonhomograph words by utilizing a phoneme detection task. Since previous research has shown that misstressed nonhomographs (nonsense words) have an adverse effect on lexical access, it might be expected that a subject's reaction time (RT) to a target phoneme following a correctly stressed nonhomograph would be faster than a subject's RT to a target phoneme following an incorrectly stressed nonhomograph. Likewise, it might be expected that subject RTs to phoneme targets following correctly stressed homographs would be faster than RTs to targets following incorrectly stressed homographs. Therefore, the purpose of the present investigation was to determine, during lexical access, whether subject RTs to word-initial phonemes would be faster when a correctly stressed word (homograph or nonhomograph) preceded the target than when an incorrectly stressed word preceded the target.

\section{METHOD}

\section{Speaker}

An experienced male speaker with a theatrical background recorded the experimental tape. All recording was done in a doublewalled, sound-treated room (IAC 402). A two-channel cassette deck (Aiwa L300) and a microphone (Nakamichi CM-100) were used to record all instructions and stimulus sentences.

\section{Materials}

Eighteen pairs of sentences were constructed to compare subject RTs for varying lexical stress in bisyllabic homograph and nonhomograph (common) words. Ten of the 18 sentence pairs shared a two-syllable homograph (noun form and verb form). Each sentence of a pair was presented in two forms: (1) correct pronunciation of stress and (2) incorrect pronunciation of stress. For example:

$$
\begin{aligned}
& \text { Mary was a recent CONvert (f)rom Catholicism. } \\
& \text {-1st syllable correct stress } \\
& \text { - Homograph = Noun } \\
& \text { Mary was a recent conVERT (f)rom Catholicism. } \\
& \text {-1st syllable incorrect stress } \\
& \text { - Homograph = Verb } \\
& \text { John needed to conVERT (f)or purposes of marriage. } \\
& \text {-2nd syllable correct stress } \\
& \text {-Homograph = Verb } \\
& \text { John needed to CONvert (f)or purposes of marriage. } \\
& \text {-2nd syllable incorrect stress } \\
& \text { - Homograph = Noun }
\end{aligned}
$$

The initial phoneme of the word immediately following the homograph in each sentence pair was the target phoneme (in parentheses). Since each homograph pair had 4 associated stimulus sentences, 40 stimulus sentences were generated from the 10 homograph pairs (see Appendix A). In one case, the stimulus word pair was not a homograph, that is, "message"/"massage." However, when "message" was misstressed, the resulting word was "massage," in regard to English phonotactics (/mesadz/ $\rightarrow /$ masaz/).

To ensure that the stimuli were misstressed, two examiners independently examined spectrograms of the correctly and incorrectly stressed stimuli. The examiners analyzed these spectrograms in terms of stressed vowel duration to determine which syllable actually received lexical stress. It was logical to presume that the syllable that received lexical stress would have a correspondingly lengthened vowel segment. There was $100 \%$ agreement between the examiners as to which syllable received lexical stress as measured by stressed vowel duration.

Since the lexical stress of homograph words dictated whether a certain homograph would be a noun or a verb, the use of nonhomograph (common) words was of particular interest in the present investigation. That is, if subjects' RTs were influenced by whether a particular homograph was a noun or a verb (first- or secondsyllable stress, respectively), it would be convenient to be able to compare subjects' homograph RTs with their common-word RTs, where a change in stress did not necessarily dictate a change in the part of speech of a word. The change in lexical stress of the twosyllable common words utilized in the present study always resulted in the formation of a nonsense word, that is, a meaningless phonetic string. Also, the use of common words allowed comparison of results with the research, mentioned above, that examined word recognition when lexical stress shifts created nonsense words (Small \& Bond, 1982; Cutler \& Clifton, 1984).

The remaining eight pairs of experimental sentences shared a twosyllable, common word. Lexical stress was placed on the first syllable of the common word in one sentence of each pair and on the second syllable of the common word in the second sentence of each 
pair. Four of the sentence pairs were constructed so that correct lexical stress occurred on the first syllable of the common word in one of the two sentences; the other four sentence pairs were constructed so that correct lexical stress occurred on the second syllable of the common word in one of the two sentences. For example:

I made a /pinat/ butter sandwich for lunch.

(1st syllable correct)

I made a /ponut/ butter sandwich for lunch. (1st syllable incorrect)

I have a /kəmplelnt/ for the manager of this store. (2nd syllable correct)

I have a /knmplant/ for the manager of this store (2nd syllable incorrect)

Sixteen stimulus sentences were constructed from the eight common words utilized (see Appendix B). The common words were pronounced in observance of English phonotactics, so that when lexical stress shifts occurred, vowel quality changes were apparent; full vowels were pronounced in their reduced forms, and reduced vowels were given full weight. Five practice sentences with no stress errors were also constructed to condition the subjects to the task.

An instructional phrase was presented before each practice and test sentence to inform the subject of the target sound in each sentence. For example, "Listen for the sound /p/ as in pig. Ready." A printed list of instructional phrases was mounted on the wall in front of the subject. In this manner, each subject was provided with simultaneous auditory and visual information regarding the target sound. This procedure had been used previously by Rastatter and Gallaher (1982).

Five seconds of silence were left between each of the stimulus sentences on the tape recording. The practice sentences were numbered 1 through 5 on the stimulus tape. The 56 stimulus sentences, containing either a homograph or a common-word stimulus, were randomized, recorded, and numbered 6 through 61 .

\section{Subjects}

The experimental task was administered to 46 right-handed female undergraduate students attending Bowling Green State University. Only native English speakers with no history of hearing or speech problems were used in the study. All subjects received partial class credit for their participation in the study.

\section{Procedure}

The present investigation utilized a phoneme monitoring task, which measured subject RTs to word-initial target phonemes following two-syllable homographs and two-syllable nonhomograph words. The reason the target phoneme was positioned after the homograph or real-word stimuli was to assure that lexical access of the preceding stimulus word had occurred.

This procedure was previously utilized by Foss, Harwood, and Blank (1980). Foss et al. indicated that subject RTs to phoneme targets located on a real word were similar to RTs for phoneme targets located on a nonsense word. However, subject RTs were significantly slower to a target phoneme immediately following a nonsense word than they were to a phoneme target immediately following a real word. Foss et al. suggested that a subject's RT to targets following a nonsense word would be slower because the nonsense item was not in the listener's mental lexicon. Therefore, it would be difficult for a listener to determine the word boundary for the nonsense item. In this case, the RT would be slower to the following target phoneme than it would be to a target following a real word, for which a word boundary could be identified more quickly.

Each subject was told that she would be listening to 61 sentences (including the five practice sentences) through a pair of headphones.
She was instructed to press a response button when a particular target phoneme was heard. The subject was seated so that her right elbow was placed on an armrest and her right hand was placed directly on top of the response panel. The subject was told to press the response button, with her right hand, as quickly as possible after hearing a particular target phoneme.

The experimental equipment used for the study was arranged in two adjacent sound-treated booths (IAC 402); an observation window was located between the booths. The experimental tape was played on a two-channel cassette recorder (Aiwa L300) located in the experimenter's sound booth. The instructional phrases were presented on the recorder's left channel, the practice and test sentences were presented on the right and left channels. The Aiwa recorder's left channel was connected to a speech audiometer (Grason Stadler 162), which amplified the experimental stimuli to a level of $85 \mathrm{~dB}$ SPL. The instructional phrases and practice/test sentences were transmitted from the audiometer to the subject in the adjacent booth via TDH 39 headphones. The stimuli were presented diotically. A microphone (Unisphere B) was connected to the audiometer, which permitted communication through the subject's headphones.

The recorder's right channel delivered the practice and test sentences to a low-pass filter (Allison 2BR) and a dc amplifier (Sanborn 850-1300B). The filter had a frequency range of $60-1080 \mathrm{~Hz}$, with a roll-off rate of $30 \mathrm{~dB} /$ octave above $1000 \mathrm{~Hz}$. The filter was used so that an equal amount of acoustic energy would trigger a voice-operated relay (Grason Stadler E7300-1) for each practice and test sentence. The dc amplifier increased the intensity level of the auditory stimuli delivered to the voice-operated relay. The relay, in turn, activated a digital timer (CMC 7078) capable of reading $1 \mathrm{msec}$.

A response panel (BCI Programmer SR4000) was located in the subject's booth. The response panel was connected to the digital timer in the experimenter's booth. The digital timer, which was triggered by the onset of each stimulus sentence, stopped when the subject pressed the response button. Since a subject's RT to hearing a particular target phoneme (following a common wond or homograph) was of specific interest, the following calculations were performed.

A digital sona-graph (Kay 7800) and sona-graph printer (Kay 7900 ) were used to perform spectrographic analyses of the test sentences. Duration measurements were calculated by measuring the length of each test sentence $(1 \mathrm{~mm}=8.05 \mathrm{msec}$ ) from the onset of each sentence to the onset of the word-initial target phoneme immediately following the homograph or common word. Peterson and Lehiste's (1960) criteria for determining syllable boundaries were adopted to determine the location of the onset of the wordinitial target phonemes. To obtain reliable measurements, the spectrograms were measured independently by two of the authors (L.S. and J.G.).

Subject RTs were read from the digital timer for the 56 experimental sentences. These RTs represented a combination of the subject's motor response time and processing time from the onset of each experimental sentence to the time the target phoneme was recognized. The spectrographic duration measurements (1) were subtracted from the reaction time values read from the digital timer (2). The mathematical difference between these values (i.e., 2 minus 1) yielded the time difference between the onset and subject detection of the word-initial target phioneme immediately following the homograph and common word stimuli.

\section{RESULTS}

In some instances, the $\mathbf{4 6}$ original subjects failed to respond entirely to a given target phoneme. Approximately $50 \%$ of the subjects in the study had one or more nonresponses for the 56 stimulus sentences. Four subjects 
were eliminated (without replacement), since they had a large proportion of nonresponses (at least $10 \%$ nonresponses). For the remaining $\mathbf{4 2}$ subjects, nonresponses were initially coded as a missing value. There were 76 instances of nonresponses among the $\mathbf{4 2}$ subjects analyzed (approximately $3 \%$ of the 2,352 possible responses). These nonresponses were evenly distributed across all words for both the homograph and common-word stimuli; there was no apparent pattern to the subjects' nonresponses.

The dependent variable, at least originally, was subjects' RTs to the target phoneme. Analysis of the data set was initially difficult. The large number of missing values could not be estimated easily from the data, and the missing values contributed to a quite unbalanced design. In a sense, however, there was some information present, regarding the missing values. Since the missing values represented nonresponses, the RT could be considered as being infinite. Although analysis of the data set with a mixture of infinite and finite values was difficult, a simplification was considered: the reciprocal transformation (Kirk, 1968, p. 66).

The reciprocal transformation simply involved creating a new dependent variable; this was the reciprocal of the original dependent variable. Transformations, like the reciprocal transformation, frequently alleviate problems with nonnormality and heteroskedascity (unequal variances). A reciprocal transformation had a simple interpretation in the present investigation, the reciprocal of a subject's RT represented the speed of response. A low value for RT corresponded to a high value for speed of response. Conversely, a high value for RT corresponded to a low value for speed of response. An infinite value for RT (that is, a nonresponse) corresponded to a speed value of zero. By analyzing the data with a reciprocal transformation, and thereby treating nonresponses as zero speed, the large number of missing values that would have been present, using the untransformed data, was avoided.

\section{Common-Word Analysis}

The common-word data were analyzed by analysis of variance (ANOVA), utilizing a four-factorial design. One factor, type, had two levels to represent whether a word was spoken (1) correctly or (2) incorrectly. The second factor, stress, had two levels: actual stress normally placed (1) on the first syllable or (2) on the second syllable. The third factor, word, had four levels and was nested within stress. This factor was treated as a random effect. The fourth factor, subject, had 42 levels and was also analyzed as a random effect.

Since word and subject were random effects, a quasi $F$ ratio $\left(F^{\prime}\right)$ was used to analyze the data (Kirk, 1968, pp. 212-214). An analysis of the statistical diagnostics revealed a residual plot of the data that produced evidence of one and possibly several extreme data points, or outliers, most likely indicative of an anticipatory subject response. The one obvious outlier was removed (subject $=18$, word $=1$, type $=1$, and stress $=1$; speed of response $=5 \mathrm{msec}$ ), and the data were reanalyzed. It appeared that this extreme data point inflated mean square error and made all of the tests for main effects and interactions nonsignificant. Although other less obvious outliers appeared in the data set, their deletion did not have any significant impact on the analysis.

The new analysis (with the outlier removed) showed a nonsignificant $F$ ratio for stress $\left[F^{\prime}(54,266)=1.654\right.$, $p>.10]$. There appeared to be no difference in subjects' speed of response when the actual lexical stress was located in either the first or the second syllable of a common word.

There was a significant $F$ ratio for type $\left[F^{\prime}(1,13)=\right.$ $29.65, p<.01]$, which was masked by the outlier in the original analysis. Subjects' speed of response was faster when phoneme targets followed correctly stressed common words. The interaction between word and type $\left[F^{\prime}(6,245)=3.01, p<.01\right]$ was also significant. This implies that the influence of how a word was spoken (correctly or incorrectly) on speed of response varied from word to word. This interaction is graphically displayed in Figure 1. This figure shows the speed of response averaged across the 42 subjects for all combinations of stress, type, and word. A posteriori tests on the word $\times$ type interaction were employed to compare correct versus incorrect stress for each of the eight common words (Bonferroni, $p<.05)($ Kirk, 1968, p. 79). There was a significant difference for stress pronunciation for all of the common words except for the words "predict" and "contain." It can be seen that for each common word, correct stress had a uniformly higher average speed than incorrect stress. The source of the interaction appeared to be the differing gap (difference in speed) between correct and incorrect pronunciation of the common words. Larger gaps appeared for words in which the actual stress was placed on the first syllable; smaller gaps appeared for words in which the actual stress was normally placed on the second syllable. However, the stress $\times$ type interaction was found to be nonsignificant $\left[F^{\prime}(1,12)=2.63\right.$, $p>$.10]. There appeared to be no difference in subjects' speed of response to targets following correctly/incorrectly stressed common words, when examined in terms of which syllable normally received lexical stress. Due to the nature of the statistical design, the significance of the word $x$ type interaction possibly could have masked a significant stress $\times$ type interaction.

\section{Homograph Analysis}

A reciprocal transformation was employed in analysis of the homograph data; nonresponses were replaced with zeroes, as in the common-word analysis. A three-factorial ANOVA was employed. One factor, type, had four levels to represent whether the homograph was stressed correctly or incorrectly, as either a noun or a verb. That is, type $=1$ implies a noun-homograph with correct lexical stress; type $=2$ implies a noun-homograph with incorrect lexical stress; type $=3$ implies a verb-homograph with correct lexical stress; type $=4$ implies a verb-homograph with 


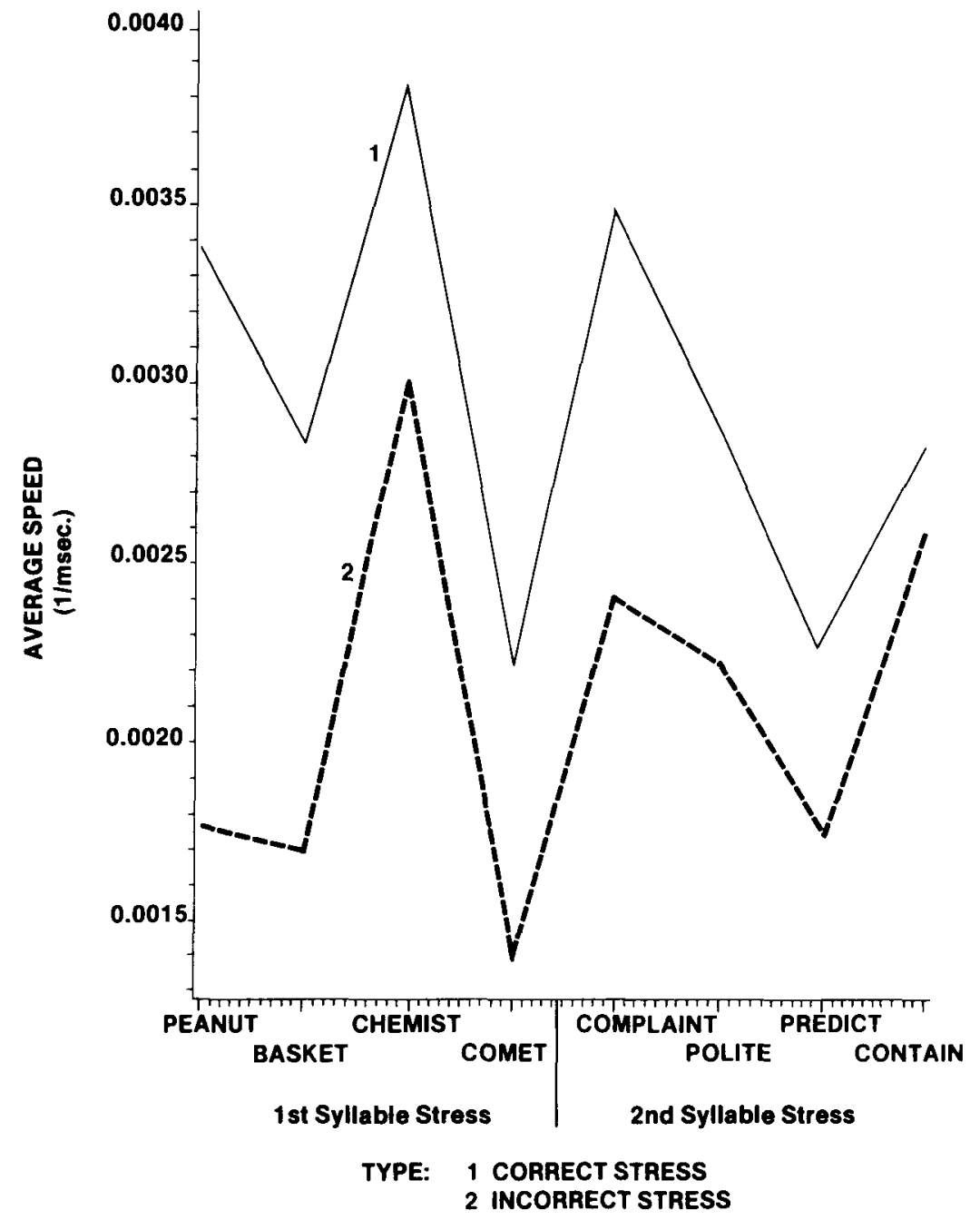

Figure 1. Common word interaction plot of subjects' speed of response for the factors word, stress, and type.

incorrect lexical stress. The second factor, word, had 10 levels, and the third factor, subject, had 42 levels. Both word and subject were treated as random effects.

A study of the ANOVA's diagnostics revealed a residual plot with one obvious outlier (subject $=2$, type $=4$, and word $=5$; speed of response $=3 \mathrm{msec}$ ) and several other possible outliers. The $F$ ratio for type was nonsignificant $\left[F^{\prime}(3,34)=1.65, p>.10\right]$. Unlike common words, correct stress did not appear to have a uniformly higher average speed than incorrect stress for the homographs. This was true whether the homograph was a noun or a verb. However, the obvious outlier appeared to inflate mean square error and masked the presence of a significant word $\times$ type interaction $\left[F^{\prime}(27,1106)=7.69, p<.01\right]$. The other outliers had no significant impact on the analysis.

The presence of a significant interaction between word and type implies that the influence of type on the average speed of response varied from word to word. This interaction is graphically represented in Figure 2 . A posteriori tests were used to investigate the difference among the average speeds for each of the four levels of type within each homograph (Bonferroni, $p<.05$ ). The interaction plot showed no clear pattern. In only two instances did correct stress have a significantly faster average speed of response for a target phoneme; the correct stress of the noun-homographs "DIgest" and "CONvict" had significantly higher average speeds of response (for a target phoneme) than for the other three types of stress possible. In no case did correct stress of a verb-homograph result in a significantly higher speed of response to a particular phoneme target. In one case, incorrect lexical stress of the verb-homograph conTRACT resulted in a significantly faster speed of response to a phoneme target than did incorrect stress of the noun-homograph CONtract (see Figure 2).

\section{DISCUSSION}

When the segmental (vowel) and suprasegmental (lexical stress) aspects of the two-syllable common words were 


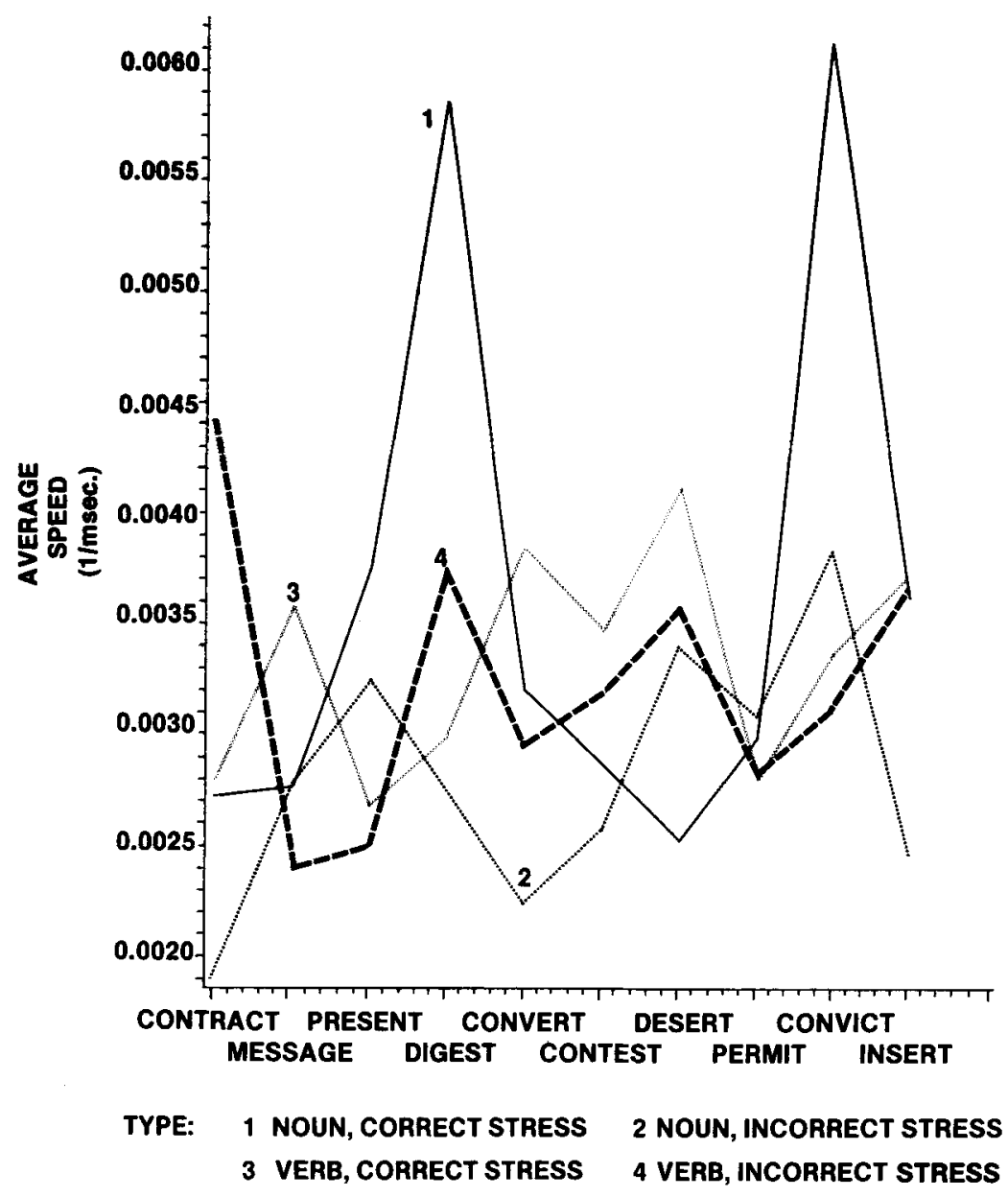

Figure 2. Homograph interaction plot of subjects' speed of response for the factors word and type.

altered, lexical access appeared to be disrupted. However, the segmental and suprasegmental changes associated with the alteration of the homographs were apparently not as disruptive in lexical access. It is interesting that the changes in vowel quality, when stress was shifted, appeared to have no effect on lexical access of the homographs. The most obvious difference between the stress changes associated with the common and homograph words was that the lexical stress shifts in common words always produced a nonsense word, whereas lexical stress shifts in homographs always produced another English word.

\section{Common-Word Analysis}

The ANOVA for the common-word analysis showed that subjects' speed of response to target phonemes were quite similar, regardless of which syllable ordinarily received lexical stress in the preceding common word. However, subjects' speed of response were faster to target phonemes following a correctly stressed common word than following an incorrectly stressed common word.
It appeared that nonsense words (meaningless phonetic strings) had some effect on lexical access. This appeared to be true whether stress was shifted to the first or to the second syllable. Since a meaningless phonetic string revealed no appropriate match in a listener's mental lexicon, the speed of response to a phoneme target was slowed because more time was devoted to lexical look-up; listeners had to search the mental lexicon for a longer period of time before realizing that the "word" heard did not exist in the lexicon. This result is consistent with Small and Bond's (1982) and Cutler and Clifton's (1984) findings, which also indicated that misstressing words had an effect on word recognition when nonsense words were utilized as stimuli.

It will be recalled that the gaps between subjects' speed of response to correct/incorrect stress were larger for common words that received normal first-syllable stress than for the common words that received second-syllable stress; however, the difference was not significant (Figure 1). Of the four common words with stress normally occurring on the second syllable, in two instances there 
was a nonsignificant difference in speed of response for correct versus incorrect stress of a common word, that is, for the stimuli "preDICT" and "conTAIN." When these two words were examined in terms of their location in the stimulus sentence, the particular target phoneme associated with them, or their frequency of occurrence in English (Kucera \& Francis, 1967), there did not appear to be any particular reason why they were treated differently by the subjects.

When we examined common words with normal secondsyllable stress, it became obvious that when lexical stress was shifted to the first syllable, the vowel in the first syllable changed from a reduced form to a form with full weight, for example, /pradikt/ $\rightarrow$ /pridakt/. When this stress shift occurred, a quite acceptable pronunciation of "predict" resulted for the first syllable. (That is, a perfectly acceptable pronunciation of "predict" could be /pridikt/.) However, the pronunciation of the vowel in the second syllable was quite different from the original when stress was shifted (/pridakt/). If a listener heard the first syllable pronounced adequately, perhaps the second syllable need not have been as precisely articulated if a listener could make use of contextual information in order to overcome the segmental (vowel) incongruity.

According to the cohort theory of word recognition (Marslen-Wilson \& Welsh, 1978), words are recognized after an initial speech segment of a word is heard and a pool of word candidates is activated. Recent research has shown the length of this initial speech segment, that is, syllable length, to be $150 \mathrm{msec}$ (Salasoo \& Pisoni, 1985; Small \& Bond, 1986; Tyler, 1984). According to Salasoo and Pisoni (1985), while the first $150 \mathrm{msec}$ of acoustic information is being gathered by a listener, contextual cues appear to help guide selection of words for the initial cohort. In the present study, when the stress shifted from the second syllable to the first for the common words, it was possible that the sentential context helped to overcome the incongruity at the phonetic level in the second syllable, that is, a combination of top-down and bottom-up processing. If this is true, then it would be expected that subjects' speed of response to target phonemes following common words with correct/incorrect lexical stress would be similar. This may account for the small gaps for subjects' speed of response between correct/ incorrect lexical stress for common words in which stress normally occurs on the second syllable.

\section{Homograph Analysis}

Although the ANOVA for the homograph analysis revealed that there was a significant interaction between the individual homograph words and the way in which they were pronounced (correctly/incorrectly as a noun or a verb), there was no clear-cut pattern as in the case of the common-word analysis. Unlike common words, when listeners heard a mispronounced homograph (noun or verb), their speed of response to a target phoneme did not appear to vary as a function of whether a particular homograph was pronounced correctly/incorrectly. There was also no evidence that a syllable effect existed; subjects' speed of response did not appear to vary in relation to whether a noun-homograph (first syllable) or a verbhomograph (second syllable) was pronounced correctly or incorrectly. Apparently, as long as a real English word preceded the phoneme target, lexical access proceeded undisturbed. This appeared to be true whether or not the stress pattern of a homograph was lexically correct.

In two instances, the listeners' response speed was significantly faster to targets following correctly pronounced homographs, that is, for the noun-homographs "DIgest" and "CONvict" (Figure 2). This finding may possibly be explained by examining the sentences in which these two words were located. In the first case, "digest" was located in the sentence, "Please buy a Reader's Digest (f)or me." Since the word "digest" was used as part of the proper name for a well-known magazine, the listeners may have experienced a lexical priming effect when listening for the target phoneme /f/ (in parentheses). That is, listeners may have been able to quickly retrieve the word "digest" from the mental lexicon on the basis of semantic and syntactic redundancies in the stimulus sentence. Therefore, listeners' attention would be more quickly directed to the phoneme following the word "digest," in this case the target phoneme /f/. Likewise, the homograph "convict" was located in a sentence that also could have caused a lexical priming effect for the listeners, that is, "After many years in jail, the studious convict (p)assed the bar exam." In this case, the word "jail" could have directed the listeners" attention to the homograph "convict," thereby increasing listeners' speed of response to the target phoneme /p/. Lexical priming effects in word recognition, due to the semantic relatedness of words in sentences, have also been documented by Blank and Foss (1978).

It is possible that in the case of homographs, listeners in the present study may have paid closer attention to the intonation contour of a stimulus sentence than to the lexical stress of individual words during word recognition, since the listeners' speed of response to target phonemes that followed correctly or incorrectly stressed homographs was similar. In an examination of intonation contour in speech perception, Cutler (1976) reported that subject RTs were faster for phoneme targets in words in which a sentence's intonation contour cued sentence accent for a target word than they were for sentences that did not cue sentence accent for a target: Cutler suggested that upcoming sentence stress location was utilized by a listener as part of the word recognition process. Likewise, Shields, McHugh, and Martin (1974) examined the role of intonation contour in word recognition. They discovered that subject RTs were faster to target phonemes in stressed words (in sentences) than to target phonemes in destressed words. However, when these target-bearing words were spliced out of the original sentences and embedded in a string of nonsense words, RTs were not significantly different between stressed and destressed target-bearing words. According to Shields et al., the rhythmical con- 
text of the sentence made it possible for listeners to respond more quickly to stressed than to destressed targets. When the words were embedded in the nonsenseword string, the rhythmical context was absent.

It was also possible that listeners in the present study utilized prosodic information in a hierarchical manner when hearing mispronounced homographs. That is, although lexical stress may have been incorrectly produced in an utterance, such a mispronunciation may have gone undetected by a listener if prosodic information could be utilized effectively in perception at a level other than at the word level. Martin (1972) supports such a view of hierarchical prosodics perception. According to Martin, there is a hierarchical, internalized temporal structure that organizes the various sound elements of speech. The location of each sound element along the time dimension is determined relative to the location of all other elements in the sequence, which in turn is constrained by the underlying temporal structure. Martin states that, in real time, certain elements in speech perception, such as accent, should be more predictable than others. His theory suggests that it is possible for a listener to predict, on the basis of a speaker's prosodic contour, the occurrence of accented syllables. Therefore, a listener would anticipate a speaker's production of accented syllables during conversation, once he became accustomed to an individual's prosodic pattern.

In the present investigation, a listener may have made predictions regarding lexical stress of a homograph due to the intonation contour of a stimulus sentence. Since lexical stress was actually incorrect, the listener may not have "heard" the misstressed item if intonation contour and sentence accent were being utilized to predict occurrence of accented syllables during lexical access.

When we examined the case for the common words, it did not appear that, upon hearing a nonsense word, subjects utilized information provided by sentence intonation contour to overcome an abberant lexical stress pattern. Had the sentence stress information been utilized in perception, no difference in speed of response to target phonemes would have occurred for the cases of correct/ incorrect stress of the common words. When a misstressed word resulted in a nonsense word, perhaps the lexical information was disruptive enough to render hierarchical stress information useless. It is possible to assume that listeners utilized sentence accent to overcome lexical stress errors only when the stress change resulted in another English word, as in the homograph case.

In conclusion, when listeners heard a misstressed word that resulted in a nonsense word, lexical access appeared to be disrupted. However, misstressed homographs did not appear to have the same effect on listeners' performance during word recognition, since misstressed homographs resulted in a real English word. These findings can be explained simply in terms of whether the word preceding the target phoneme was located in a listener's mental lexicon during lexical look-up. When the word preceding the target phoneme was a real English word, lexical access did not appear to be affected. However, when the word preceding the target phoneme was a nonsense word, lexical access was slowed, since the nonsense word did not exist in the listeners' mental lexicon. This resulted in a correspondingly slower speed of response to the target phoneme.

In the case of homographs, changes in lexical stress were not sufficiently aberrant to disrupt lexical access, even though changes in vowel quality were evident. When listeners heard a misstressed homograph (a real word), it was possible that they utilized sentence accent to overcome the problem of incorrect lexical stress during word recognition.

\section{REFERENCES}

Blank, M. A., \& Foss D. J. (1978). Semantic facilitation and lexical access during sentence processing. Memory \& Cognition, 6, 644-652. Brown, R., \& McNeILL, D. (1966). The tip of the tongue phenomenon. Journal of Verbal Learning \& Verbal Behavior, 5, 325-337.

CoLE, R. A., JAkImIK, J. (1980). How are syllables used to recognize words? Joumal of the Acoustical Society of America, 67, 965 .

Cutler, A. (1976). Phoneme-monitoring reaction time as a function of preceding intonation contour. Perception \& Psychophysics, 20, 55-60.

Cutler, A., \& Clifton, C. (1984). The use of prosodic information in word recognition. In H. Bouma \& D. G. Bouwhuis (Eds.), Attention and performance: $X$. Control of language processes (pp. 183196). Hillsdale, NJ: Erlbaum.

Cutler, A., \& Foss, D. J. (1978). On the role of sentence stress in sentence processing. Language \& Speech, 20, 1-10.

FAY, D. A., CUTLER, A. (1977). Malapropisms and the structure of the mental lexicon. Linguistic Inquiry, 8, 505-520.

Foss, D. J., Harwood, D. A., Blank, M. A. (1980). Deciphering decoding and devices. In R. A. Cole (Ed.), Perception and production of fluent speech (pp. 165-199). Hillsdale, NJ: Erlbaum.

KIRK, R. E. (1968). Experimental design: Procedures for the behavioral sciences. Belmont, CA: Brooks/Cole.

KuČera, H., \& Francis, W. N. (1967). Computational analysis of present day American English. Providence, RI: Brown University Press.

LeHISTE, I. (1970). Suprasegmentals. Cambridge, MA: MIT Press.

Marslen-Wilson, W. D., \& Welsh, A. (1978). Processing interactions and lexical access during word recognition in continuous speech. Cognitive Psychology, 10, 29-63.

MARTIN, J. G. (1972). Rhythmic versus serial structure in speech and other behaviors. Psychological Review, 79, 497-509.

Peterson, G. E., Lehiste, I. (1960). Duration of syllable nuclei in English. Joumal of the Acoustical Society of America, 32, 693-703.

Rastatter, M. P., \& Gallaher, A. J. (1982). Reaction times of normal subjects to monaurally presented verbal and tonal stimuli. Neuropsychologica, 20, 465-473.

SAlASOO, A., \& Pisoni, D. (1985). Interaction of knowledge sources in spoken word identification. Journal of Memory \& Language, 24, 210-231.

Shields, J. L., McHugh, A., \& MARTin, J. G. (1974). Reaction time to phoneme targets as a function of rhythmic cues in continuous speech. Joumal of Experimental Psychology, 102, 250-255.

Small, L. H., \& Bond, Z. S. (1982, November). Effects of mispronunciations on lexical access in continuous speech perception. Paper presented at the meeting of The American Speech-Language Hearing Association, Toronto.

Small, L. H., * Bond, Z. S. (1986). Distortions and deletions: Wordinitial consonant specificity in fluent speech. Perception \& Psychophysics, 40, 20-26.

TYLER, L. K. (1984). The structure of the initial cohort: Evidence from gating. Perception \& Psychophysics, 36, 417-427. 


\section{APPENDIX A}

\section{Homograph Sentence Pairs*}

1. Vacationers traveling through Asia can conTRACT/CONtract (M)alaria in India, China and the Philippines.

Yesterday, Dave Steib signed a conTRACT/CONtract $(\mathrm{m})$ aking him the richest player in baseball.

2. I scheduled a back mesSAGE/MESsage (F)riday night. You received an urgent mesSAGE/MESsage (f)rom the boss.

3. What type of preSENT/PREsent (d)id you buy mom this year?

The government will preSENT/PREsent (D)ecember's inflation figures tonight.

4. Please buy a Reader's diGEST/Dlgest (f)or me.

It takes more time to diGEST/DIgest (f)ood as you grow older.

5. Mary was a recent conVERT/CONvert (f)rom Catholicism. John needed to conVERT/CONvert (f)or purposes of marriage.

6. She tried to conTEST/CONtest (M)ary's will.

There was a conTEST/CONtest (M)onday night.

7. The desERT/DESert (p)lain is barren and colorless.

He will desERT/DESert (P)aul on the island.

8. A six-month parking perMIT/PERmit (f)or my car costs twenty dollars.

Wood County does not perMIT/PERmit (f)arm equipment on the highway.
9. After many years in jail, the studious conVICT/CONvict (p)assed the bar exam.

Radical governments conVICT/CONvict (p)eople before they are found guilty.

10. Wednesday's Sentinel inSERT/INsert (g)ives the food specials for the week.

The typesetter was told to inSERT/INsert (g)rocery specials on page one.

*Target phonemes in parentheses.

\section{APPENDIX B}

\section{Common-Word Sentence Pairs*}

Correct Stress-First Syllable

1. I made a peanut-/ponst/ (b)utter sandwich for lunch.

2. Take this basket-/bosket/ (f)ull of apples into the kitchen.

3. The young chemist-/komlst/ (p)roduced a cream to fade wrinkles.

4. Halley's comet-/kəmet/ (s)cared men, women and children.

Correct Stress-Second Syllable

1. I have a complaint-/kımplont/ (f)or the manager of this store.

2. They have polite-/polot/, (k)indly employees at Food Town.

3. I predict-/pridəkt/ (s)unny weather all week long.

4. The corral will contain-/kantan/ (f)orty or so horses.

*Target phonemes in parentheses.

(Manuscript received August 31, 1987;

revision accepted for publication March 10, 1988.) 